\title{
Effect of Hypophysectomy on the Synaptic Ribbons in the Pineal Organ of the Killifish Fundulus heteroclitus
}

\author{
Yuri OMURA*1 and M. A. Ali*2 \\ (Received March 11, 1982)
}

\begin{abstract}
The Pineal organ of the killifish was investigated by electron microscopy under experimental light and dark conditions and after hypophysectomy. Significant changes were detected in the number and length of the synaptic ribbons in the pineal organ. The pineal synaptic ribbons increased in number and length during darkness at night, but decreased during the day in light. Hypophysectomy showed a prominent effect on the decrease in number and length of the synaptic ribbons. This result suggests that the pineal synaptic ribbons function as receptors for the information from the pituitary. Meanwhile, the intact fish kept in continuous darkness showed a conspicuous decrease in number and length of the synaptic ribbons during day time. This means that changes of synaptic ribbons (number and length) might be involved in circadian rhythm rather than light and dark conditions.
\end{abstract}

Recent studies on several species of fishes have shown the effect of pinealectomy on the gonadal and pituitary activity, liver and plasma metabolites, locomotor activity, color change, etc. ${ }^{1-6)}$ However, there is little information of the neural and humoral control, including the effect of hypophysectomy, on the pineal organ of the fish. In contrast, it has already been demonstrated that the gonadectomy and hypophysectomy significantly affect the change in volume and cellular structure of the pineal gland of mammals. ${ }^{7-10)}$ As mentioned previously ${ }^{11)}$ synaptic ribbons in the pineal organ of the trout, Salvelinus fontinalis and Salmo gairdneri, sampled during the day in light and the night in darkness show dramatic changes. In addition, circadian changes of synaptic ribbons have been demonstrated in the mammalian pineal ${ }^{12-18)}$ and in the fish retina. ${ }^{17,18)}$ Although there is little information on the direct effect of hypophysectomy on pineal synaptic ribbons, it is known that the quantitative change in number of synaptic ribbons in the rat pinealocytes occurred after orchidectomy. ${ }^{10}$ ) Therefore, the present paper deals with the effect of hypophysectomy, environmental lighting and day-night change on the synaptic ribbons in the pineal organ of the killifish Fundulus heteroclitus kept under experimental conditions.

\section{Materials and Methods}

A total of 18 male killifish Fundulus heteroclitus were used in this experiment. They were brought to Hiram from the New York Aquarium and kept on a short-day-length $(8 \mathrm{hrL} / 16 \mathrm{hrD})$, in artificial sea water. ${ }^{1 \text { (日) }}$ Hypophysectomy was performed at the end of May 1979 by the modified method of Abramowitz. ${ }^{19)}$ All fishes were weighed and measured at the time of surgery, and their nuptial colors recorded. After an interval of two months (to allow for complete regression of the target organs of the pituitary), the fish were re-examined. Any fish that increased more than $1 \mathrm{~mm}$ in length, or had failed to pass into sexual regression, as judged by the fading of nuptial coloration, was rejected. The presumed absence of the pituitary was confirmed by dissection at autopsy.

Eight intact and 8 hypophysectomized fish were divided into 2 parallel groups of 8 fish in each. Group 1 consisted of fish that had been maintained on a short-day-length and autopsied during the day $(10.00-11.00$, hypophysectomized fish; $14.00-$ 15.00 , intact fish). Group 2 consisted of fish that had been maintained on a short-day-length and ones kept in total darkness for 3 days, shielded by lightproof covers. Group 2 was autopsied during the night (20.30-22.00), under a dim red light. Two other intact fish were maintained in total

\footnotetext{
*1 Fisheries Laboratory, Faculty of Agriculture, Nagoya University, Chikusa, Nagoya 464, Japan (大村 百合: 名古屋大学裴学部水産学教室).

*2 Départment de Biologie, Université de Montréal, C. P. 6128, Succursale "A", Montréal, Québec, H3C $3 J 7$, Canada (モントリオール大学生物学科).
} 


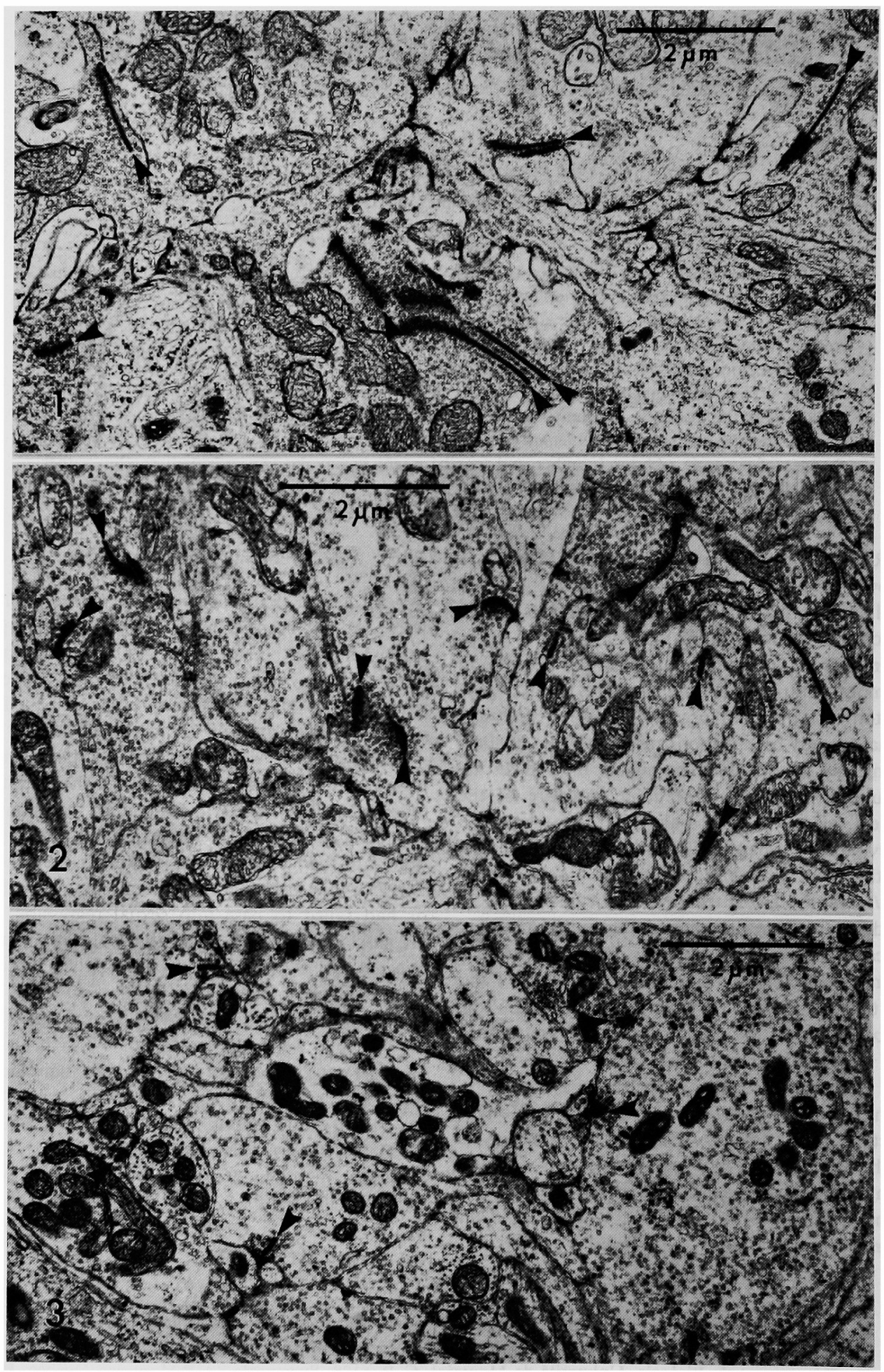


Table 1. Changes in number and length of the synaptic ribbons in the pineal organ of the killifish Fundulus heteroclitus under the experimental conditions

\begin{tabular}{|c|c|c|c|c|c|c|c|c|c|c|}
\hline \multicolumn{3}{|c|}{ Experimental conditions } & \multicolumn{3}{|c|}{ Ratio of SR to SY (SR/SY) } & \multicolumn{3}{|c|}{ Length of SR $(\mu \mathrm{m})$} & \multirow{2}{*}{\multicolumn{2}{|c|}{$\begin{array}{c}\text { Ratio of SR over } \\
0.25 \mu \mathrm{m} \text { to } \\
\text { total SR }\end{array}$}} \\
\hline Treatment & Adaptation & Fixation & Num & oer & Mean & $0.25-0.5$ & $0.5-1.0$ & $1.0<$ & & \\
\hline Intact & Light & Day & $66 / 46$ & $31 / 21$ & $\begin{array}{l}1.455 \\
\pm 0.020\end{array}$ & 29 & 15 & 3 & $47 / 97$ & $48.4 \%$ \\
\hline Hypect & Light & Day & $35 / 33$ & $71 / 86$ & $\begin{array}{l}1.052 \\
\quad \pm 0.008\end{array}$ & 33 & 8 & 0 & $41 / 106$ & 38.6 \\
\hline Intact & Dark & Night & $281 / 171$ & -* & 1.643 & 130 & 59 & 13 & $202 / 281$ & 71.8 \\
\hline Hypect & Dark & Night & $26 / 35$ & $63 / 65$ & $\begin{array}{l}0.856 \\
\quad \pm 0.113\end{array}$ & 18 & 4 & 2 & $24 / 89$ & 26.9 \\
\hline Intact & Dark & Day & $53 / 48$ & $20 / 16$ & $\begin{array}{l}1.177 \\
\pm 0.073\end{array}$ & 30 & 15 & 0 & $45 / 73$ & 61.6 \\
\hline
\end{tabular}

* No synapses (SY) and synaptic ribbons (SR) are found under the present observation.

darkness for 3.5 days and autopsied during the day (11.30-12.00), under a dim red light.

The fish were decapitated at the termination of the experiment and initially the whole brain together with its skull was fixed at room temperature in $2 \%$ paraformaldehyde $+1 \%$ glutaraldehyde buffered at pH 7.3 with $0.092 \mathrm{M}$ cacodylate for 0.5-1 hr. The pineal organ was then dissected out and replaced in the same fixative for 1-4 hr or overnight. Dark-adapted specimens were processed until the removal of non-pineal tissues under a dim red light. After washing for $1 \mathrm{hr}$ in cold $0.1 \mathrm{M}$ cacodylate buffer containing $8 \%$ sucrose the specimens were postfixed in cold $1.3 \%$ osmium tetroxide buffered at pH 7.3 with $0.067 \mathrm{M}$ s-collidine for 1.5-2 hr, dehydrated in a graded series of ethanol and embedded in Spurr's epoxy resin.

In each specimen five meshes (each one included ten $60-80 \mathrm{~nm}$ cross sections) were obtained from three portions in the pineal end vesicle. In total 150 sections were cut with glass knives from each specimen. These sections, stained with $3 \%$ uranyl acetate and $0.2 \%$ lead citrate, were then examined under a JEM $100 \mathrm{~S}$ electron microscope at $80 \mathrm{KV}$. Due to the irregularity in distribution of the pineal neuropils low magnification $(\times 5,000)$ photographs of the synaptic region were taken. Finally the synaptic ribbons and synapses were counted, and the ratio between them (sr/sy) com- pared. In addition, the lengths of synaptic ribbons were measured.

\section{Results}

In this paper the changes in number and length of the pineal synaptic ribbons were investigated under several experimental conditions of illumination and after hypophysectomy. A summary of the results is given in Table 1 and Figs. 1-6. The frequency of appearance of the synaptic ribbons is indicated by the ratio of sr/sy (number of synaptic ribbons to number of synapses), as it is not convenient to express the value per unit area due to the irregularity in the distribution of the pineal neuropils.

It can be seen that significant differences are observed between light- and dark-adaptation, intact and hypophysectomized, and between day and night. Under these experimental conditions the dark-adapted, intact fish showed the highest value (1.643) of $\mathrm{sr} / \mathrm{sy}$ with the majority $(71.8 \%)$ of the synaptic ribbons longer than $0.25 \mu \mathrm{m}$ in length (Table 1 and Fig. 6). As Fig. 1 indicates, synaptic ribbons measuring approximately $1 \mu \mathrm{m}$ in length frequently appear apart from the synaptic site in the photoreceptor basal process. Compared to the dark-adapted, intact fish; the light-adapted, intact one (Fig. 2) showed a lower value $(1,455)$ of

Figs. 1-5 show the distribution of synaptic ribbons in the pineal organ of the killifish Fundulus heteroclitus kept under various experimental conditions. In each figure arrow heads indicate synaptic ribbons.

Fig. 1. Synapse area in the pineal organ of the dark-adapted, intact killifish. A number of long synaptic ribbons are located with synaptic vesicles and mitochondria in the photoreceptor basal processes.

Fig. 2. Synapse area of the pineal organ in the light-adapted, intact killifish. A few longer and several shorter synaptic ribbons can be seen in the photoreceptor basal processes.

Fig. 3. Synapse area of the pineal organ in the light-adapted, hypophysectomized killifish. A few short synaptic ribbons may be found in the presynaptic site of the photoreceptor basal processes. 
sr/sy with approximately half $(51.6 \%)$ of the synaptic ribbons shorter than $0.25 \mu \mathrm{m}$ in length (Table 1 and Fig. 6).
Hypophysectomy appears to have an effect on both light- and dark-adapted fish. It decreased both the number and length of the synaptic ribbons.

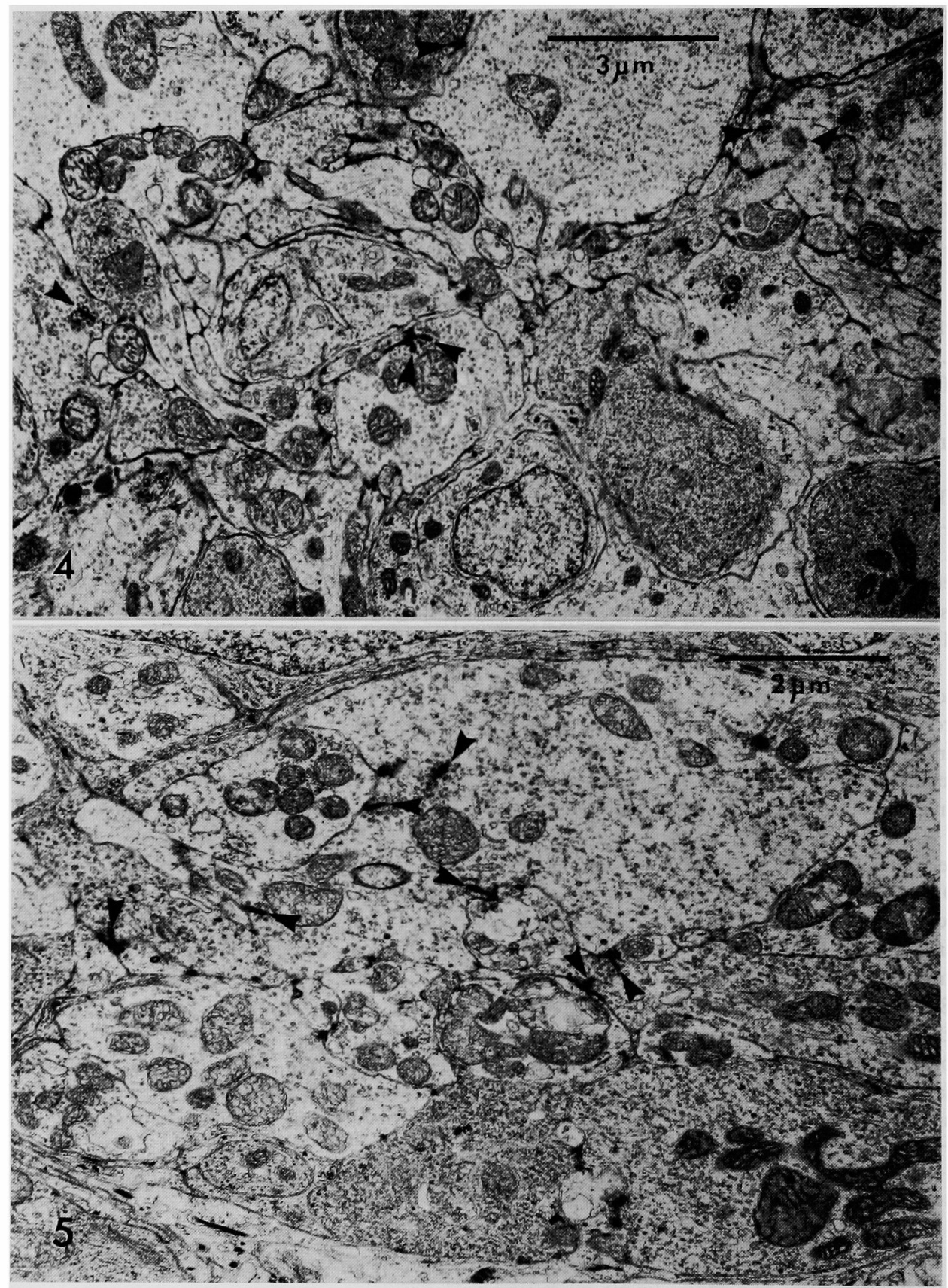

Fig. 4. A lower magnification picture of the pineal organ in the dark-adapted, hypophysectomized killifish contains a few short synaptic ribbons in the photoreceptor basal processes.

Fig. 5. Synapse area in the pineal organ of the dark-adapted, intact killifish sampled during the daytime. Several short synaptic ribbons can be seen in the photoreceptor basal processes. 


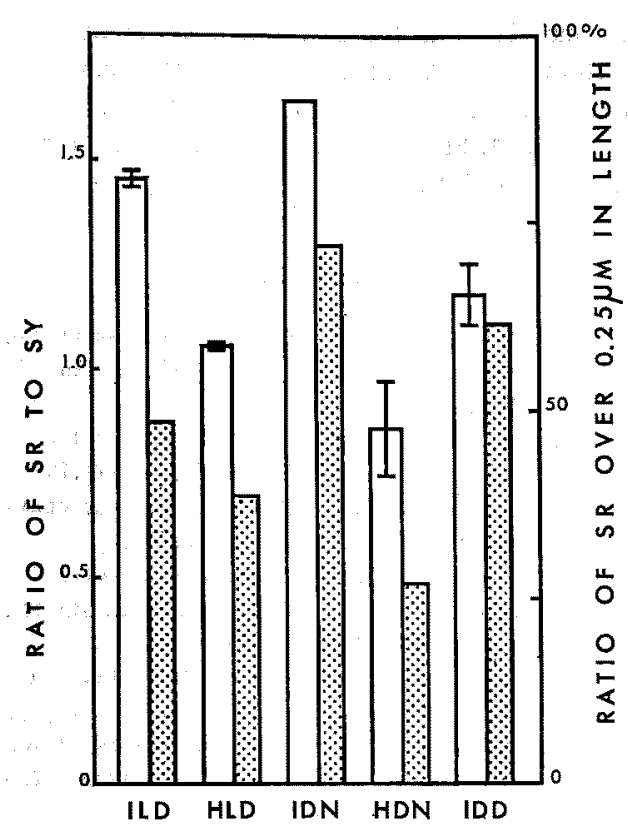

Fig. 6. Histogram showing the changes in number (clear) and length (stippled) of the synaptic ribbons in the pineal organ of intact (I) and hypophysectomized (H) killifish Fundulus heteroclitus sampled during day in light (LD), night in dark (DN) and day in dark (DD). The vertical bars represent standard deviations of mean.

In comparison to the light-adapted, intact fish; the light-adapted, hypophysectomized one (Fig. 3) showed a lower value (1.052) of sr/sy and included fewer $(38.6 \%)$ synaptic ribbons more than $0.25 \mu \mathrm{m}$ in length (Table 1 and Fig. 6). Similarly, the dark-adapted, hypophysectomized fish (Fig. 4) had a lower value $(0.856)$ of sr/sy and fewer $(26.9 \%)$ synaptic ribbons measuring more than $0.25 \mu \mathrm{m}$ in length (Table 1 and Fig. 6) than the dark-adapted intact fish.

The time of fixation also appears to have an effect on the synaptic ribbons. The dark-adapted, intact fish fixed durign the daytime (Fig. 5) had a lower value (1.177) of sr/sy and fewer (61.6\%) synaptic ribbons measuring more than $0.25 \mu \mathrm{m}$ (Table 1. and Fig. 6) than the dark-adapted, intact fish fixed during the night (Fig. 1).

\section{Discussion}

As mentioned in a previous paper, ${ }^{11)}$ there is a difference in the appearance of synaptic ribbons of pineal photoreceptor cells between the light- and dark-adapted trout, Salvelinus fontinalis and Salmo gairdneri. The present investigation quantitatively ascertains the fact that the pineal synaptic ribbons of the killifish Fundulus heteroclitus increase in number and length during the night in darkness but decrease during the day in light.

Although its function is not completely understood, the synaptic ribbon is a typical component of receptor cells of sensory organs (viz. retina, vestibular organ, etc.), which forms part of a synapse and seems to play an integral role in sensory, synaptic transmission. Similarly, in the pineal organ of lower vertebrates, it can be interpreted that the synaptic ribbon of the photoreceptor cell is primarily involved in sensory, synaptic transmission. However, as mentioned in this paper, the ratio of $\mathrm{sr} / \mathrm{sy}$ (number of synaptic ribbons to number of sensory synapses) often indicates values higher than 1. In addition, the synaptic ribbons are frequently located apart from the synaptic site. This raises the question of whether the synaptic ribbons of the fish pineal are merely playing a role in sensory, synaptic transmission, or are they involved in other functions similar to those of the mammalian pineal. Based on the results of quantitative investigations carried out under experimental conditions on the pineal organ of the guinea pig, it has been suggested that the synaptic ribbons of the mammalian pinealocytes, derived from the pineal photoreceptor cell of the lower vertebrates, may be involved in intercellular communication to govern the secretory activity of the pineal organ.12).

In the pineal organ of the intact killifish, the synaptic ribbons increase in number and length during the night but decrease during the day even in total and continuous darkness. This result implies that such a change in appearance of synaptic ribbons is definitely not affected by environmental lighting, but appears to be dependent on the day-night shift or circadian change. Knowledge concerning circadian rhythm of the synaptic ribbons has been accumulated from mammalian pinealocytes $^{12-16)}$ and fish retina. ${ }^{17,19)}$ According to VOLlRATH $^{12)}$ and WAGNER and ALI, ${ }^{18}$ ) a characteristic oscillation in the number of synaptic ribbons seems to be controlled by endogenous factors rather than external stimuli. In addition, consideration of available facts shows that the pineal organ of the fish may be involved in the control of the circadian rhythm or daily variation of locomotor activity in the lake chub, ${ }^{b)}$ color change in the killifish, ${ }^{\beta)}$ liver and plasma metabolites in 
the goldfish, ${ }^{8)}$ etc. Moreover, it has been demonstrated that in the rainbow or steelhead trout, rhythmical fluctuations of the pineal hormone, melatonin, and its synthetic enzyme, hydroxyindoleO-methyltransferase, are associated with the daynight change. ${ }^{20,21)}$ Accordingly, it is possible to suggest that in the pineal organ of the fish, the synaptic ribbons, in addition to the involvement in the sensory synapse, may be involved in the circadian rhythmicity of melatonin-synthesis, locomotor activity, color change, liver and plasma metabolites, etc.

The present paper demonstrates that hypophysectomy has a marked effect on the decrease in number and length of synaptic ribbons of the pineal organ, both in light- and dark-adapted killifish. This finding is comparable to that in the mammalian pineal organ showing that the function of the pineal is depressed by hypophysectomy. ${ }^{7-9)}$ In a quantitative morphological study of the mouse pineal, Ito and Matsushima ${ }^{\text {7) }}$ showed that hypophysectomy induced a marked decrease in the pineal volume, and correlated it with a marked atrophy of pineal cells throughout the entire organ. Moreover, in rats intense or considerable ultrastructural changes of the pineal organ after hypophysectomy (viz. atrophy of endoplasmic reticulum, Golgi apparatus, mitochondria, etc. and depletion of secretory granules) have been reported by LUPULESCU ${ }^{8)}$ and SATODATE et al. ${ }^{\text {9) }}$ However, the direct effect of hypophysectomy on the pineal synaptic ribbons has apparently not been reported previously but it has been shown that gonadectomy causes a prominent increase in the number and size of synaptic ribbons of the rat pinealocytes ${ }^{10)}$ with a slight increase in the pineal volume of the mouse. ${ }^{\text {? }}$

In the light of these findings, it may be interpreted that in the killifish, the pituitary is involved in the endogenous control of the pineal organ and that the pineal synaptic ribbons function as receptors for information from the pituitary. However, further investigations are necessary to clarify the pituitary involvement in the control of the pineal function in the fish.

\section{Acknowledgements}

We thank Prof. G. E. PICKFord for providing the material and for carrying out the hypophysectomies and Prof. M. OGURI for his valuable advice. We are also grateful to Dr. M. A. KLYNe and Miss M. PERTwee for assistance with the preparation and for reading the manuscript.

\section{References}

1) H. URASAKI: J. Exp. Zool., 185, 241-246 (1973).

2) V. L. de Vlaming: Gen. Comp. Endoc., 26, 3649 (1975).

3) G. Delahunty, G. Bauer, M. Prack, and V. de Vlaming: Gen. Comp. Endoc., 35, 99-109 (1978).

4) M. J. VodicniK, R. E. KRAL, and V. L. de VlaMING: J. Fish. Biol., 12, 187-196 (1978).

5) M. Kavaliers: J. Exp. Zool., 209, 33-40 (1979).

6) M. Kavaliers, B. T. Firth, and C. L. Ralph: Can. J. Zool., 58, 456-460 (1980).

7) T. Ito and S. Matsushrma: Anat. Rec., 162, 479-482 (1968).

8) A. Lupulescu: Experientia, 24, 482-484 (1968).

9) R. Satodate, K. S. Hsieh, and M. Ohta: Experientia, 26, 638-640 (1970).

10) M. KARASEk: J. Neural Trans., 38, 149-157 (1976).

11) Y. Omura and M. A. Ali: Cell Tiss. Res., 208, 111-122 (1980).

12) L. Vollrath: Z. Zellforsch., 145, 171-183(1973)

13) L. Vollrath and C. Howe: Cell Tiss. Res., 165, 383-390 (1976).

14) K. Kurumado and W. Mori: Cell Tiss. Res., 182, 565-568 (1977).

15) K. Kurumado and W. Mori: Cell Tiss. Res., 208, 229-235 (1980).

16) T. S. KING and W.J. Dougherty: $A m$. $J$. Anat., 157, 335-343 (1980).

17) H.J. WAGNER: in "Vision in Fishes" (ed. by M. A. ALI), Plenum, New York, 1975, pp. 679686.

18) H. J. WAGNER and M. A. AlI: Can. J. Zool. 55, 1684-1691 (1977).

19) M. A. Ali and G. E. Pickford: Rev. Can. Biol. 38, 139-144 (1979).

20) J. R. SMith and L. J. Weber: Can. J. Zool., 54, 1530-1534 (1976).

21) W. A. Gern, D. W. Owens, and C. L. Ralph: J. Exp. Zool., 205, 371-376 (1978). 